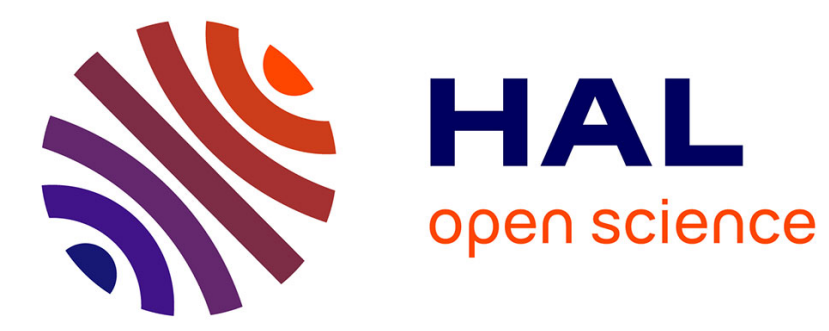

\title{
Self-efficacy and return to work in cancer survivors: Current knowledge and future prospects
}

\author{
Bertrand Porro, Angela G E M de Boer, Monique H W Frings-Dresen, Yves \\ Roquelaure
}

\section{- To cite this version:}

Bertrand Porro, Angela G E M de Boer, Monique H W Frings-Dresen, Yves Roquelaure. Self-efficacy and return to work in cancer survivors: Current knowledge and future prospects. European Journal of Cancer Care, 2020, 29 (6), pp.e13304. 10.1111/ecc.13304 . hal-02930168

\section{HAL Id: hal-02930168 https://hal.science/hal-02930168}

Submitted on 10 Mar 2021

HAL is a multi-disciplinary open access archive for the deposit and dissemination of scientific research documents, whether they are published or not. The documents may come from teaching and research institutions in France or abroad, or from public or private research centers.
L'archive ouverte pluridisciplinaire HAL, est destinée au dépôt et à la diffusion de documents scientifiques de niveau recherche, publiés ou non, émanant des établissements d'enseignement et de recherche français ou étrangers, des laboratoires publics ou privés. 


\section{Self-efficacy and return-to-work in cancer survivors: current knowledge and future prospects}

Bertrand Porro ${ }^{1,2}$

Angela G. E. M. de Boer ${ }^{3}$

Monique H. W. Frings-Dresen ${ }^{3}$

Yves Roquelaure ${ }^{1,4}$

1 - Inserm, EHESP, Irset - UMR_S 1085, Univ. Angers, Univ. Rennes, Angers, France.

2 - EPSYLON EA 4556, Univ. Paul Valéry Montpellier 3, Univ. Montpellier, Montpellier, France.

3 - Coronel Institute of Occupational Health, Amsterdam Public Health research Institute, Amsterdam University Medical Centers, University of Amsterdam, Amsterdam, The Netherlands.

4 - Inserm, EHESP, Irset - UMR_S 1085, Univ. Angers, CHU Angers, Univ. Rennes, Angers, France. 


\section{Commentary}

\section{Introduction}

3 Self-efficacy (SE) is a cognitive mechanism based on expectations or beliefs about

4 one's ability to perform actions necessary to achieve specific goals (Bandura, 1977, 5 1997). SE affects individuals' decision-making process and subsequent actions such 6 as engaging in physical activity, changing eating behaviours, managing cancer or 7 returning to work (RTW) (Bandura, 1977, 1997; Brouwer et al., 2009). The Attitude8 Social influence-self-Efficacy model (ASE model) indicated SE as one of the main 9 behavioural determinants for RTW in patients with musculoskeletal disorders 10 (Vermeulen et al., 2009). In relation to cancer, theoretical knowledge on behavioural 11 determinants, such as SE, is still limited (Duijts, Bleiker, et al., 2017; Duijts, van 12 Egmond, et al., 2017). Knowledge on the associations between SE and RTW would 13 allow appropriate interventions to be targeted to enhance cancer survivors' RTW 14 (Duijts, Bleiker, et al., 2017; Leensen et al., 2017).

15 In the literature concerning RTW following a cancer diagnosis, SE has been 16 categorised based on three broad domains of functioning: general-SE (Koch et al., 17 2015), cancer management-SE (Bains et al., 2012) and job-SE / RTW-SE (Bains et 18 al., 2012; Leensen et al., 2017; Rosbjerg et al., 2020; Wolvers et al., 2018). Some 19 authors used a RTW-SE questionnaire to describe job-SE (Bains et al., 2012; 20 Wolvers et al., 2018) despite a temporal difference between RTW-SE and job-SE. On 21 one hand, the patient plans to RTW (RTW-SE). On the other hand, the patient has 22 RTW and plans to remain at work (job-SE). Therefore, special attention should be 23 paid to the vocabulary used to interpret results in order to avoid misunderstanding.

24 First, this commentary aims to clarify which of general-SE, cancer management-SE 25 or RTW-SE is the most relevant for occupational outcomes in cancer survivors. 
1 Secondly, we aim to discuss the questionnaires used to evaluate RTW-SE in

2 quantitative studies focusing on the RTW of cancer survivors. Finally, this

3 commentary proposes possible interventions that could enhance RTW-SE, and

4 explores future research perspectives.

6 General-SE, cancer management-SE and RTW-SE

7 According to Bandura (1997), it does not make sense theoretically to talk about

8 general-SE. No significant relationship has been found between RTW of cancer

9 survivors and general-SE or cancer management-SE, respectively (Bains et al., 10 2012; Koch et al., 2015). Conversely, cancer patients showing low levels of RTW-SE 11 are more likely to be on sick leave upon diagnosis (Bains et al., 2012) and are more 12 likely to have longer delays before full-RTW (Wolvers et al., 2018).

13 The predictive power of RTW-SE on cancer survivors' RTW should be discussed. 14 Rosbjerg et al. (2020) suggested that RTW-SE does not appear as the strongest 15 predictor of RTW among cancer patients undergoing chemotherapy. However, the 16 small sample size of this study does not permit any generalisation of this result 17 (Rosbjerg et al., 2020). Among workers with psychological or upper-body 18 musculoskeletal injuries, RTW-SE showed the strongest relationship with RTW 19 (Black et al., 2018). Job-SE also showed a strong predictive association with 20 remaining at work following a RTW attempt (Black et al., 2018).

21 To study the RTW process, there is a significant need to focus on RTW-SE. 22 Complementary investigations, within a large sample, are therefore necessary to 23 understand the strength of the association between RTW-SE and RTW in cancer 24 patients. 


\section{Questionnaires to measure RTW-SE}

2 Quantitative studies focusing on RTW-SE have generally used three questionnaires:

3 the RTWSE-19 (Shaw et al., 2011), the RTWSE-10 (Brouwer et al., 2011), or the

4 RTWSE-11 (Lagerveld et al., 2010).

5 The RTWSE-19 (Shaw et al., 2011) and the RTWSE-10 (Brouwer et al., 2011) aim to

6 assess workers' beliefs about their current ability to resume normal job

7 responsibilities following pain onset among patients with musculoskeletal disorders.

8 Although they show good predictive validity for RTW of patients with musculoskeletal

9 disorders (Brouwer et al., 2011, 2015; Shaw et al., 2011), these questionnaires do

10 not appear totally appropriate for patients with cancer. These scales do not question

11 the patients' beliefs in their abilities to face problems with decreased cognitive

12 functioning and increased emotional distress, induced by cancer treatments, in order

13 to RTW (de Boer et al., 2015; Duijts et al., 2014; Porro, Bertin, et al., 2019; Porro,

14 Michel, et al., 2019).

15 The RTWSE-11 (Lagerveld et al., 2010) integrates beliefs in the patients' abilities to 16 support the physical (e.g., "I can deal with the physical demands of my work"), the 17 cognitive (e.g., "I will be able to concentrate on my work"), the emotional (e.g., "I 18 won't be able to complete my work tasks due to my emotional state"), the relational 19 (e.g., "I won't be able to handle potential problems at work") and the professional 20 (e.g., "I will be able to perform my tasks at work") aspects of the work environment 21 that have been identified as strong predictors of RTW following a cancer diagnosis 22 (de Boer et al., 2015; Gragnano et al., 2018; Porro, Bertin, et al., 2019). However, 23 there is no consensus on the factor structure of this questionnaire. Lagerveld et al. 24 (2010) defend a one-dimensional questionnaire without having used factor analysis 25 for validation. Conversely, exploratory and confirmatory analysis conducted by Silva- 
1 Junior et al. (2018) yielded a bidimensional questionnaire. To increase knowledge on

2 RTW-SE, the RTWSE-11 (Lagerveld et al., 2010) should be adapted for cancer

3 survivors by using rigorous reliability and validity testing.

4

5 Interventions

6 An interventional study has been proposed by Leensen et al. (2017), that includes

7 physical exercise and occupational counselling programmes aimed at enhancing

8 RTW-SE, work ability, and finally, the RTW of cancer patients. Despite the fact that

9 Leensen et al. (2017) showed significant increases in RTW-SE and subsequent

10 RTW-SE over time, the study lacked a control group. To evaluate the effectiveness of

11 interventions aimed at increasing RTW-SE, and promote RTW in cancer patients,

12 randomised controlled trials should be conducted. For example, a meta-analysis

13 conducted by Merluzzi et al. (2019) revealed medium effect sizes of

14 complementary/integrative medicine, social support, cognitive behaviour therapy and

15 self-management interventions in enhancing cancer patients' SE related to specific 16 behaviours (e.g., pain, physical activity, coping with cancer, and stress 17 management). This study also revealed a small/medium effect size of physical 18 activity on cancer patients' SE (Merluzzi et al., 2019).

19 In order to improve RTW-SE, several possibilities could be taken into account. 20 According to Bandura (1997), SE is enhanced through:

21 - mastery experience, which could be implemented by a progressive succession 22 of small professional tasks that are easy to carry out (Gollwitzer, 1999).

23 - vicarious experience, which could be induced with support groups focusing on 24 vocational rehabilitation after cancer (De Blasi et al., 2014). 

6

- verbal persuasion, which could be articulated around positive discourse from supervisors and colleagues (Greidanus, de Boer, et al., 2018; Greidanus, Tamminga, et al., 2018).

- physiological feedback, which refers to a virtuous circle between enhancing RTW-SE, RTW and promoting cancer management (Kennedy et al., 2007).

\section{Future research perspectives}

Leensen et al. (2017) observed temporal changes in RTW-SE followed by actual RTW. However, not all cancer patients are able to develop RTW-SE. We therefore hypothesise that there are several developmental pathways for RTW-SE. Investigating developmental trajectories of RTW-SE, and identifying their association with RTW over time, will allow for better identification of cancer patients at risk of non-RTW, in order to improve supportive care. Furthermore, knowledge on the developmental pathways of RTW-SE and its association with subsequent RTW will allow the development of innovative interventions which could be aimed at improving the RTW-SE of cancer patients, potentially leading to actual RTW.

\section{Conclusion}

RTW-SE is an emerging topic of interest in psycho-oncology for cancer patients who have not yet RTW. Research in patients with other chronic diseases has highlighted the importance of studying the association between RTW-SE and RTW (Black et al., 2018). To make this research possible in cancer patients, it is important to use reliable and valid measurements of RTW-SE. It also seems wise to investigate the temporal aspects of RTW-SE developmental pathways because of the psychological 
1 studies should revolve around the improvement of RTW-SE by integrating a

2 randomised controlled design that evaluates the effectiveness of these interventions

3 in order to improve RTW after a cancer diagnosis.

4

5

6

7

8

9

\section{References}

Bains, M., Munir, F., Yarker, J., Bowley, D., Thomas, A., Armitage, N., \& Steward, W. (2012). The impact of colorectal cancer and self-efficacy beliefs on work ability and employment status: A longitudinal study: Colorectal cancer, work ability and employment. European Journal of Cancer Care, 21(5), 634-641. https://doi.org/10.1111/j.1365-2354.2012.01335.x

Bandura, A. (1977). Self-efficacy: Toward a unifying theory of behavioral change. Psychological Review, 84(2), 191-215. https://doi.org/10.1037/0033-295X.84.2.191

Bandura, A. (1997). Self-efficacy: The exercise of control. W.H. Freeman \& Company.

Black, O., Keegel, T., Sim, M. R., Collie, A., \& Smith, P. (2018). The Effect of SelfEfficacy on Return-to-Work Outcomes for Workers with Psychological or UpperBody Musculoskeletal Injuries: A Review of the Literature. Journal of Occupational Rehabilitation, 28(1), 16-27. https://doi.org/10.1007/s10926-017-9697-y

Brouwer, S., Amick, B. C., Lee, H., Franche, R.-L., \& Hogg-Johnson, S. (2015). The Predictive Validity of the Return-to-Work Self-Efficacy Scale for Return-to-Work Outcomes in Claimants with Musculoskeletal Disorders. Journal of Occupational Rehabilitation, 25(4), 725-732. https://doi.org/10.1007/s10926-015-9580-7

Brouwer, S., Franche, R.-L., Hogg-Johnson, S., Lee, H., Krause, N., \& Shaw, W. S. (2011). Return-to-Work Self-Efficacy: Development and Validation of a Scale in Claimants with Musculoskeletal Disorders. Journal of Occupational Rehabilitation, 21(2), 244-258. https://doi.org/10.1007/s10926-010-9262-4 
1 Brouwer, S., Krol, B., Reneman, M. F., Bültmann, U., Franche, R.-L., van der Klink, J.

2 J. L., \& Groothoff, J. W. (2009). Behavioral Determinants as Predictors of Return to

3 Work After Long-Term Sickness Absence: An Application of the Theory of Planned

4 Behavior. Journal of Occupational Rehabilitation, 19(2), 166-174.

5 https://doi.org/10.1007/s10926-009-9172-5

6 De Blasi, G., Bouteyre, E., Bretteville, J., Boucher, L., \& Rollin, L. (2014).

7 Multidisciplinary department of « Return to Work After a Cancer »: A French

8 experience of support groups for vocational rehabilitation. Journal of Psychosocial

9 Oncology, 32(1), 74-93. https://doi.org/10.1080/07347332.2013.855961

10 de Boer, A. G. E. M., Taskila, T. K., Tamminga, S. J., Feuerstein, M., Frings-Dresen, 11 M. H. W., \& Verbeek, J. H. (2015). Interventions to enhance return-to-work for 12 cancer patients. The Cochrane Database of Systematic Reviews, 9, CD007569. 13 https://doi.org/10.1002/14651858.CD007569.pub3

14 Duijts, S. F. A., Bleiker, E. M. A., Paalman, C. H., \& Beek, A. J. van der. (2017). A 15 behavioural approach in the development of work-related interventions for cancer 16 survivors: An exploratory review. European Journal of Cancer Care, 26(5), 17 e12545. https://doi.org/10.1111/ecc.12545

18 Duijts, S. F. A., van Egmond, M. P., Gits, M., van der Beek, A. J., \& Bleiker, E. M. 19 (2017). Cancer survivors' perspectives and experiences regarding behavioral 20 determinants of return to work and continuation of work. Disability and 21 Rehabilitation, 39(21), 2164-2172. https://doi.org/10.1080/09638288.2016.1219924

22 Duijts, S. F. A., van Egmond, M. P., Spelten, E., van Muijen, P., Anema, J. R., \& van 23 der Beek, A. J. (2014). Physical and psychosocial problems in cancer survivors 24 beyond return to work: A systematic review. Psycho-Oncology, 23(5), 481-492. 25 https://doi.org/10.1002/pon.3467 
1 Gollwitzer, P. (1999). Implementation Intentions: Strong Effects of Simple Plans.

2 American Psychologist, 54, 493-503. https://doi.org/10.1037/0003-066X.54.7.493

3 Gragnano, A., Negrini, A., Miglioretti, M., \& Corbière, M. (2018). Common

4 Psychosocial Factors Predicting Return to Work After Common Mental Disorders,

5 Cardiovascular Diseases, and Cancers : A Review of Reviews Supporting a Cross-

6 Disease Approach. Journal of Occupational Rehabilitation, 28(2), 215-231.

7 https://doi.org/10.1007/s10926-017-9714-1

8 Greidanus, M. A., de Boer, A. G. E. M., de Rijk, A. E., Tiedtke, C. M., Dierckx de

9 Casterlé, B., Frings-Dresen, M. H. W., \& Tamminga, S. J. (2018). Perceived 10 employer-related barriers and facilitators for work participation of cancer survivors : 11 A systematic review of employers' and survivors' perspectives. Psycho-Oncology, $12 \quad$ 27(3), 725-733. https://doi.org/10.1002/pon.4514

13 Greidanus, M. A., Tamminga, S. J., de Rijk, A. E., Frings-Dresen, M. H. W., \& de 14 Boer, A. G. E. M. (2018). What Employer Actions Are Considered Most Important 15 for the Return to Work of Employees with Cancer? A Delphi Study Among 16 Employees and Employers. Journal of Occupational Rehabilitation. 17 https://doi.org/10.1007/s10926-018-9800-z

18 Kennedy, F., Haslam, C., Munir, F., \& Pryce, J. (2007). Returning to work following 19 cancer: A qualitative exploratory study into the experience of returning to work 20 following cancer. European journal of cancer care, 16(1), 17-25.

21 Koch, R., Wittekindt, C., Altendorf-Hofmann, A., Singer, S., \& Guntinas-Lichius, O. 22 (2015). Employment pathways and work-related issues in head and neck cancer 23 survivors. Head \& Neck, 37(4), 585-593. https://doi.org/10.1002/hed.23640

24 Lagerveld, S. E., Blonk, R. W. B., Brenninkmeijer, V., \& Schaufeli, W. B. (2010). 25 Return to work among employees with mental health problems : Development and 
1 validation of a self-efficacy questionnaire. Work \& Stress, 24(4), 359-375.

$2 \quad$ https://doi.org/10.1080/02678373.2010.532644

3 Leensen, M. C. J., Groeneveld, I. F., Heide, I. van der, Rejda, T., van Veldhoven, P.

4 L. J., Berkel, S. van, Snoek, A., Harten, W. van, Frings-Dresen, M. H. W., \& de

5 Boer, A. G. E. M. (2017). Return to work of cancer patients after a multidisciplinary

6 intervention including occupational counselling and physical exercise in cancer

7 patients: A prospective study in the Netherlands. BMJ Open, 7(6), e014746.

8 https://doi.org/10.1136/bmjopen-2016-014746

9 Merluzzi, T. V., Pustejovsky, J. E., Philip, E. J., Sohl, S. J., Berendsen, M., \& 10 Salsman, J. M. (2019). Interventions to enhance self-efficacy in cancer patients : A 11 meta-analysis of randomized controlled trials. Psycho-Oncology, 28(9), 1781-1790. 12 https://doi.org/10.1002/pon.5148

13 Porro, B., Bertin, M., Bonnaud Antignac, A., Petit, A., Cousson-Gélie, F., \& 14 Roquelaure, Y. (2019). Assessment of psychosocial dimensions of return to work 15 after a cancer diagnosis : Current perspectives and future opportunities. Psycho16 Oncology, 28(12), 2429-2431. https://doi.org/10.1002/pon.5235

17 Porro, B., Michel, A., Zinzindohoué, C., Bertrand, P., Monrigal, E., Trentini, F., 18 Baussard, L., \& Cousson-Gélie, F. (2019). Quality of life, fatigue and changes 19 therein as predictors of return to work during breast cancer treatment. 20 Scandinavian Journal of Caring Sciences. https://doi.org/10.1111/scs.12646

21 Rosbjerg, R., Hansen, D. G., Zachariae, R., Hoejris, I., Lund, T., \& Labriola, M. 22 (2020). The Predictive Value of Return to Work Self-efficacy for Return to Work 23 Among Employees with Cancer Undergoing Chemotherapy. Journal of 24 Occupational Rehabilitation. https://doi.org/10.1007/s10926-020-09882-2

25 Shaw, W. S., Reme, S. E., Linton, S. J., Huang, Y.-H., \& Pransky, G. (2011). 3rd 
1 place, PREMUS best paper competition: Development of the return-to-work self-

2 efficacy (RTWSE-19) questionnaire--psychometric properties and predictive

3 validity. Scandinavian Journal of Work, Environment \& Health, 37(2), 109-119.

$4 \quad$ https://doi.org/10.5271/sjweh.3139

5 Silva-Junior, J. S., Souto, E. P., Fischer, F. M., \& Griep, R. H. (2018). Validity and

6 test-retest reliability of the Brazilian version of the Return-to-work self-efficacy

7 questionnaire. Revista De Saude Publica, 52, 65. https://doi.org/10.11606/S1518$8 \quad 8787.2018052000237$

9 Vermeulen, S. J., Anema, J. R., Schellart, A. J., van Mechelen, W., \& van der Beek, 10 A. J. (2009). Intervention mapping for development of a participatory return-to-work 11 intervention for temporary agency workers and unemployed workers sick-listed due 12 to musculoskeletal disorders. BMC Public Health, 9(1). 13 https://doi.org/10.1186/1471-2458-9-216

14 Wolvers, M. D. J., Leensen, M. C. J., Groeneveld, I. F., Frings-Dresen, M. H. W., \& 15 De Boer, A. G. E. M. (2018). Predictors for earlier return to work of cancer patients. 16 Journal of Cancer Survivorship, 12(2), 169-177. https://doi.org/10.1007/s11764$17 \quad 017-0655-7$ 